\title{
SISTEM INFORMASI BERBASIS WEB UNTUK KETERSEDIAAN PISANG LOKAL JAWA BARAT DI KAMPUNG CAU PADJADJARAN
}

\author{
Amili Yohari, Irfan Ardiansah, Dwi Purnomo \\ Fakultas Teknologi Industri Pertanian, Universitas Padjadjaran \\ Email: amili14001@mail.unpad.ac.id
}

\begin{abstract}
Kampung Cau Padjadjaran (KCP) is an agency and bananas distributor that has the empowerment and utilization activities of local bananas. KCP partnered with several villages in the cities and districts of West Java, such as Sumedang, Sukabumi, Tasikmalaya, Garut, and Purwakarta. Up to now, KCP need to fulfill the market demand reaches 10 tons per week. Currently, KCP collects the data directly by visiting each village partners that each village is far enough to be visited, these are considered inefficient because it can be a waste of time and energy on the go and also the 10 tons bananas data per week is a high amount of data to be managed. To facilitate the achievement of the $K C P$ objectives as a unit that raises superior local wisdom, hence the design of the web-based information systems will be conducted that can be used to manage the KCP banana database. In addition, it is also expected to enhance the empowerment of local communities each village partner by managing the information systems. The designing is conducted through several stages, such as the early stage (field observations), the designing stage (needs analysis, user-interface web design, programming implementation) and the final stage (testing of information systems, research results and conclusion). The expected result is a system that empowers youth and improving the welfare of banana farmers by providing pertinent information availability of bananas each partner KCP village in West Java.
\end{abstract}

Keywords: Information System, Banana, KCP, West Java.

\section{PENDAHULUAN}

Indonesia terkenal dengan keanekaragaman

hayatinya di dunia, salah satunya adalah buah

pisang. Pisang merupakan komoditas

pertanian yang berpotensi untuk

dikembangkan guna mendukung ketahanan

pangan di Indonesia. Hal tersebut dibuktikan

dengan data produksi buah di Indonesia dari

Badan Pusat Statistik sebagai berikut:

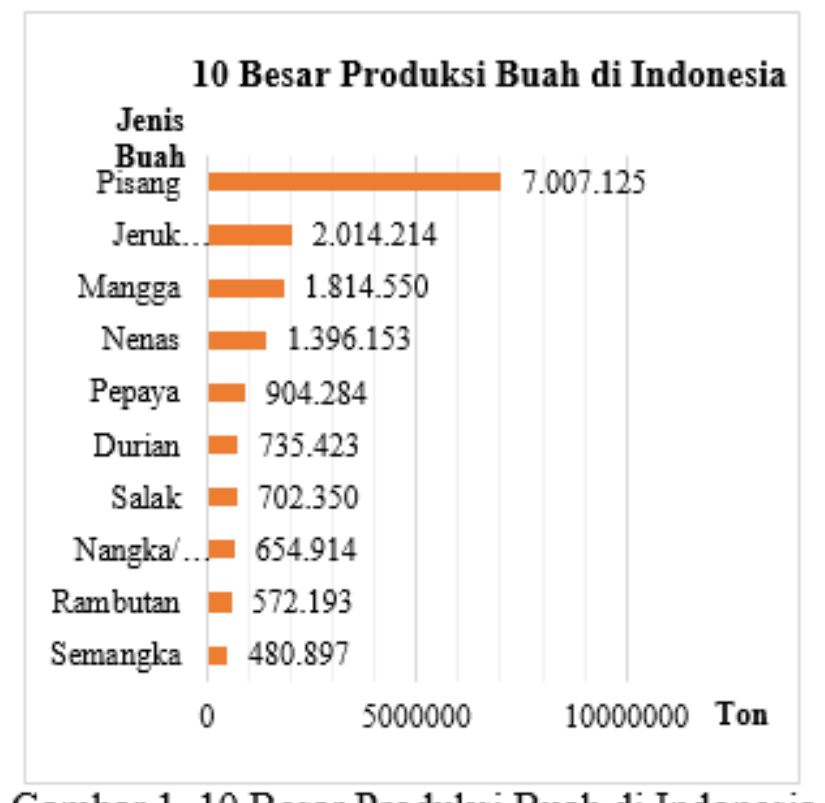

Gambar 1. 10 Besar Produksi Buah di Indonesia

Sumber: Badan Pusat Statistik, 2016 
Yohari,dkk., SISTEM INFORMASI BERBASIS ...

Gambar 1 di atas menunjukan bahwa potensi buah pisang di Indonesia cukup tinggi, pisang menempati peringkat pertama dalam 10 besar produksi buah di Indonesia dengan jumlah sebanyak 7 juta ton pada tahun 2016, diikuti oleh buah jeruk, mangga, nenas, papaya, durian, salak, nangka, rambutan, dan semangka (BPS, 2016). pisang lokal serta berperan dalam rantai pasok pisang, dimulai dari petani hingga industri produk turunan pisang. KCP sebagai sumber pasok macam-macam pisang diantaranya Pisang Kapas, Pisang Nangka, Pisang Ambon, dan lain-lain, serta mempunyai beberapa desa mitra yang tersebar di Jawa Barat, di antaranya Sumedang, Garut, Tasikmalaya, Cianjur, dan Sukabumi (Ismail, Hesya, Cau, \& Kcp, 2016).

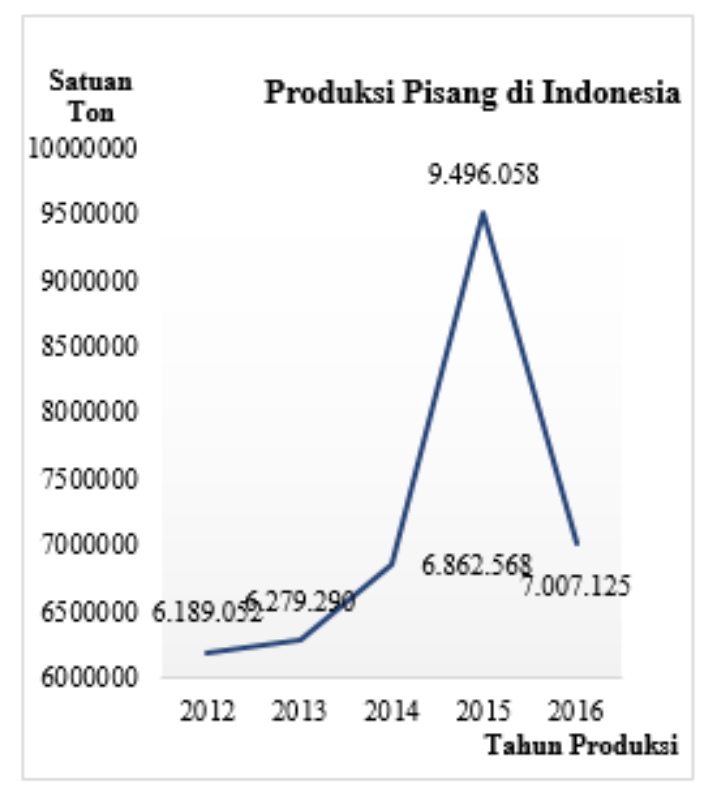

Gambar 2. Produksi Pisang di Indonesia

Sumber: Food and Agriculture Organization of the United Nation, 2016

Gambar 2 menunjukkan produksi buah pisang dari tahun 2012 hingga 2015 mengalami kenaikan dengan jumlah produksi tertinggi sebanyak 9,49 juta ton di tahun 2015, namun pada tahun 2016 jumlah tersebut menurun menjadi 7 juta ton (FAO, 2016).

Kampung Cau Padjadjaran (KCP) merupakan sebuah lembaga yang ada di Fakultas Pertanian, Universitas Padjadjaran, dan mempunyai kegiatan terkait pengembangan dan pemanfaatan sumber daya
KCP belum memiliki sistem informasi yang dapat mengelola ketersediaan pisang lokal tiap desa mitranya dan melakukan kegiatan transaksi dan pemesanan pisang secara konvensional dengan mendatangi langsung tiap desa mitra, hal tersebut dinilai tidak efisien karena jarak lokasi tiap desa mitra yang cukup jauh serta dapat membuang waktu ditambah dengan permintaan pasar akan pisang yang cukup tinggi jika mengacu pada grafik produksi pisang di atas. 
Yohari,dkk., SISTEM INFORMASI BERBASIS

Menurut Apăvăloaie (2014), untuk bersaing dan mengembangkan bisnisnya, sebuah organisasi perlu mengadopsi teknologi baru, dan internet merupakan teknologi yang dapat membantu siapapun dalam mencari suatu informasi dengan cepat, efisien, dan kaya akan sumber daya, dengan kata lain sebuah sistem informasi berbasis web. Situmorang (2013) di dalam penelitiannya menyatakan bahwa internet bermanfaat bagi seseorang untuk melakukan transaksi secara online melalui internet. Keberhasilan sistem informasi guna membantu bisnis pada sektor pertanian juga dibuktikan oleh Pujianto, Prayudha, dan Ardiansah (2017) dalam merancang sebuah sistem informasi berbasis untuk menyediakan meningkatkan efektivitas dan efisiensi arus informasi pada PT X - yaitu sebuah perusahaan produsen selada - agar informasi atau data penting perusahaan mulai dari data produksi, pemasaran, hingga pengemasan dapat teratur dengan cepat dan akurat. Oleh karena itu, diperlukan suatu sistem informasi berbasis web yang mempunyai database ketersediaan pisang di KCP. Database tersebut diharapkan membantu proses bisnis KCP, baik dalam pengolahan, pengarsipan, maupun penyimpanan data dengan cepat dan akurat secara online tanpa membuang waktu serta tenaga dalam pelaksanaan.

\section{METODE PENELITIAN}

Perancangan database ini dilakukan dengan metode rekayasa object-oriented, yaitu dengan membangun sistem informasi berbasis web untuk manajemen persediaan pisang di Kampung Cau Padjadjaran dengan menjadikan obyek sebagai kelas-kelas yang berbeda tanpa adanya pengulangan penulisan kode lalu dihubungkan oleh setiap fungsi untuk

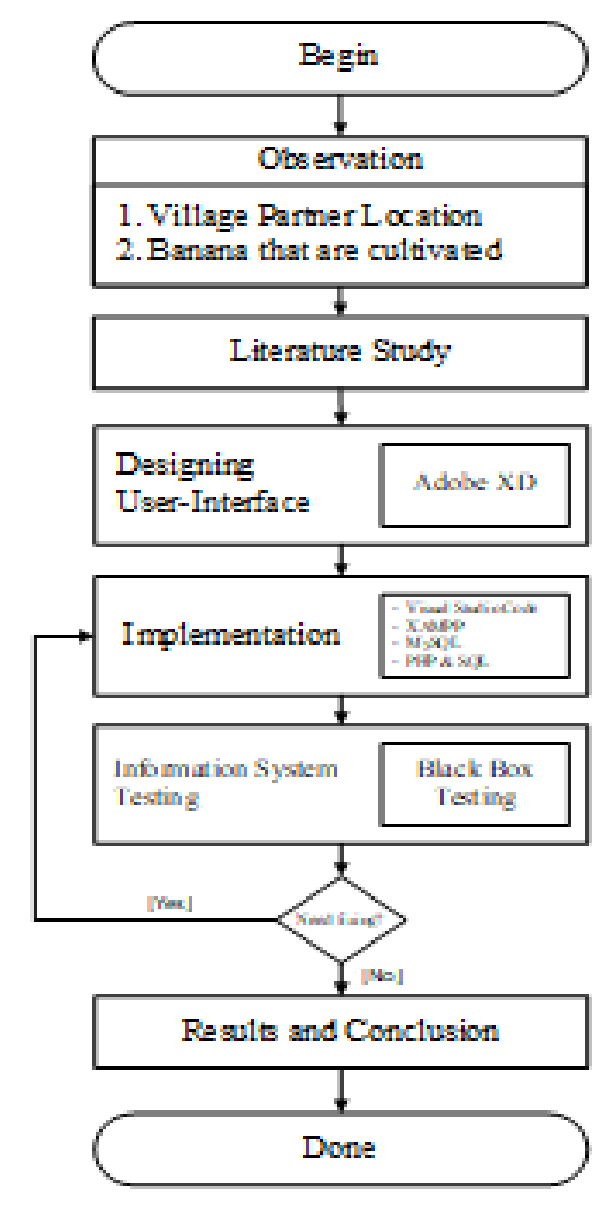

Gambar 3. Alur Perancangan 
Yohari,dkk., SISTEM INFORMASI BERBASIS ... ditampilkan menjadi suatu user-interface atau halaman web. penulisan kode program. Berikut tampilan

dari sistem informasi yang sedang dirancang:

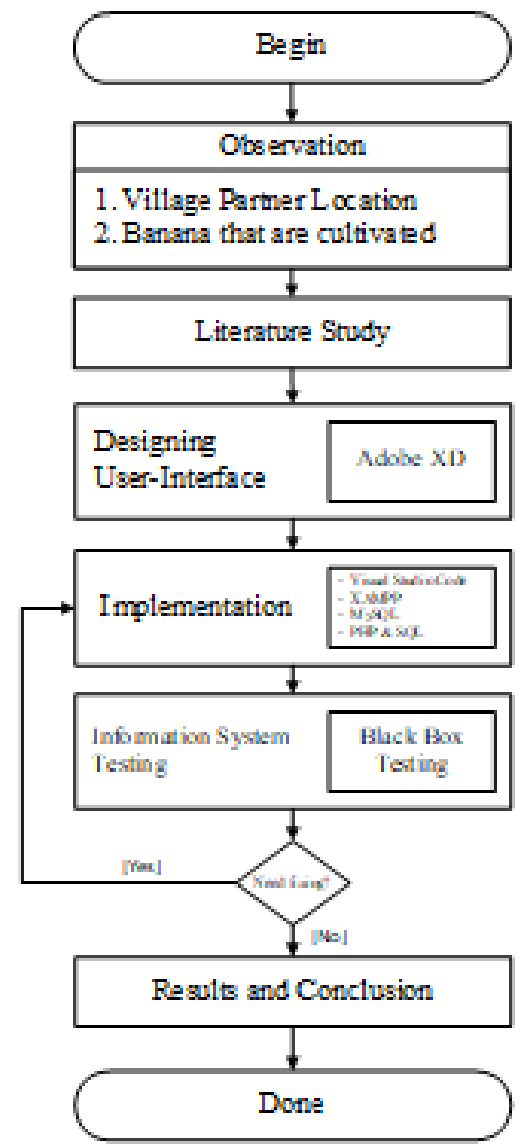

Gambar 3. Alur Perancangan

\section{Tahap Awal}

1. Observasi

Observasi atau pengamatan dilakukan secara langsung dengan mengikuti kegiatan $\mathrm{KCP}$, baik di selretariat maupun di lokasi desa mitra $\mathrm{KCP}$, untuk mengetahui semua lokasi desa mitra dan berbagai macam pisang lokal yang dibudidayakan oleh KCP.

2. Studi Literatur

Setelah melakukan observasi, studi literatur dilakukan untuk mempelajari literatur yang terkait dengan sistem informasi dan perancangannya.

\section{Perancangan Sistem Informasi}

1. Analisis Kebutuhan

Tahap ini dilakukan untuk menganalisis setiap kebutuhan sistem informasi.

2. Design Interface

Antarmuka dirancang untuk kepentingan estetika dan ergonomi dari sistem informasi.

3. Implementasi

Proses coding dilakukan untuk merancang sistem informasi sesuai dengan fungsi dan antarmuka yang diinginkan.

\section{Tahap Akhir}

1. Pengujian Sistem Informasi

Sistem infomarsi yang telah dirancang akan diuji menggunakan black-box testing untuk dianalisa fungsionalitasnya.

2. Hasil Penelitian dan Kesimpulan

Hasil penelitian yang dianalisa dengan black-box testing akan ditarik kesimpulannya.

\section{HASIL DAN PEMBAHASAN}

Perancangan sistem informasi berbasis

web ini telah sampai pada tahap implementasi 


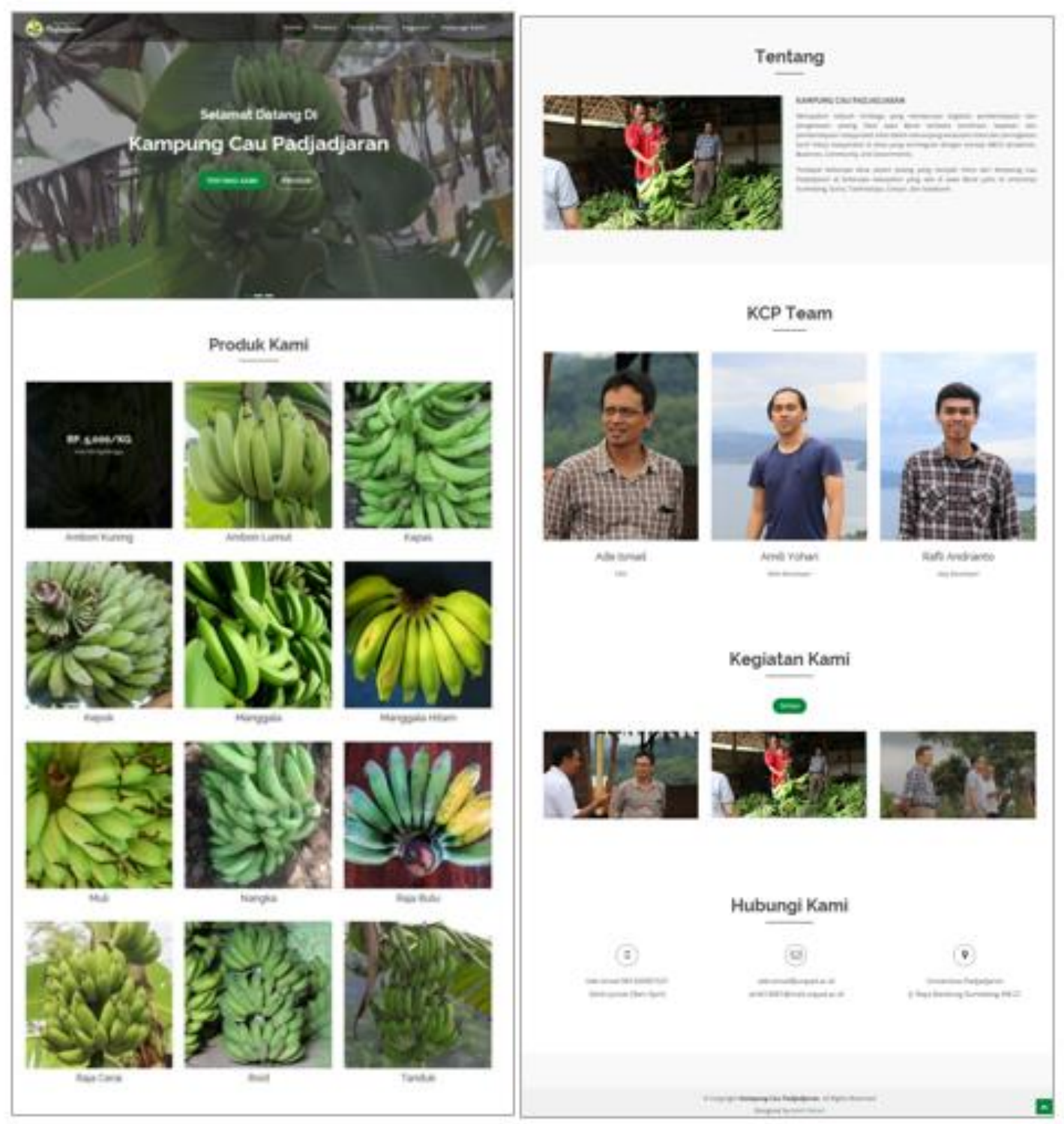

Gambar 4. Tampilan Website

Gambar 4 di atas merupakan tampilan utama dari website KCP yang dirancang meliputi navigation menu, slider greetings, product boxes, tentang perusahaan, team dari $\mathrm{KCP}$, kegiatan KCP, kontak, danfooter. Untuk product boxes, terdapat 12 boxes pisang yang beserta hover harga dan kapasitas pisang yang tersedia saat pointer diarahkan ke tiap box. Harga dan kapasitas yang ditetapkan dapat diperbaharui tiap saat secara online oleh administrator. Administrator nantinya dapat memerbaharui harga dan kapasitas dengan login melalui alamat web www.kcp.com/admin/ karena mempertimbangkan keamanan dari website maka tidak disediakan login button di halaman web utama. Berikut tampilan login box untuk administrator: 


\section{ADMIN LOGIN}

useanume

username

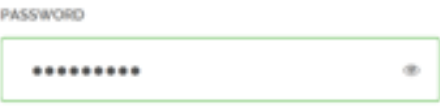

\section{Login}

Setelah memasukan username dan password, administrator dapat login untuk memperbaharui tiap harga dan kapasitas pisang yang tersedia di KCP. Berikut tampilan dari database untuk updating data pisang:

\section{Gambar 5. Administrator Login}

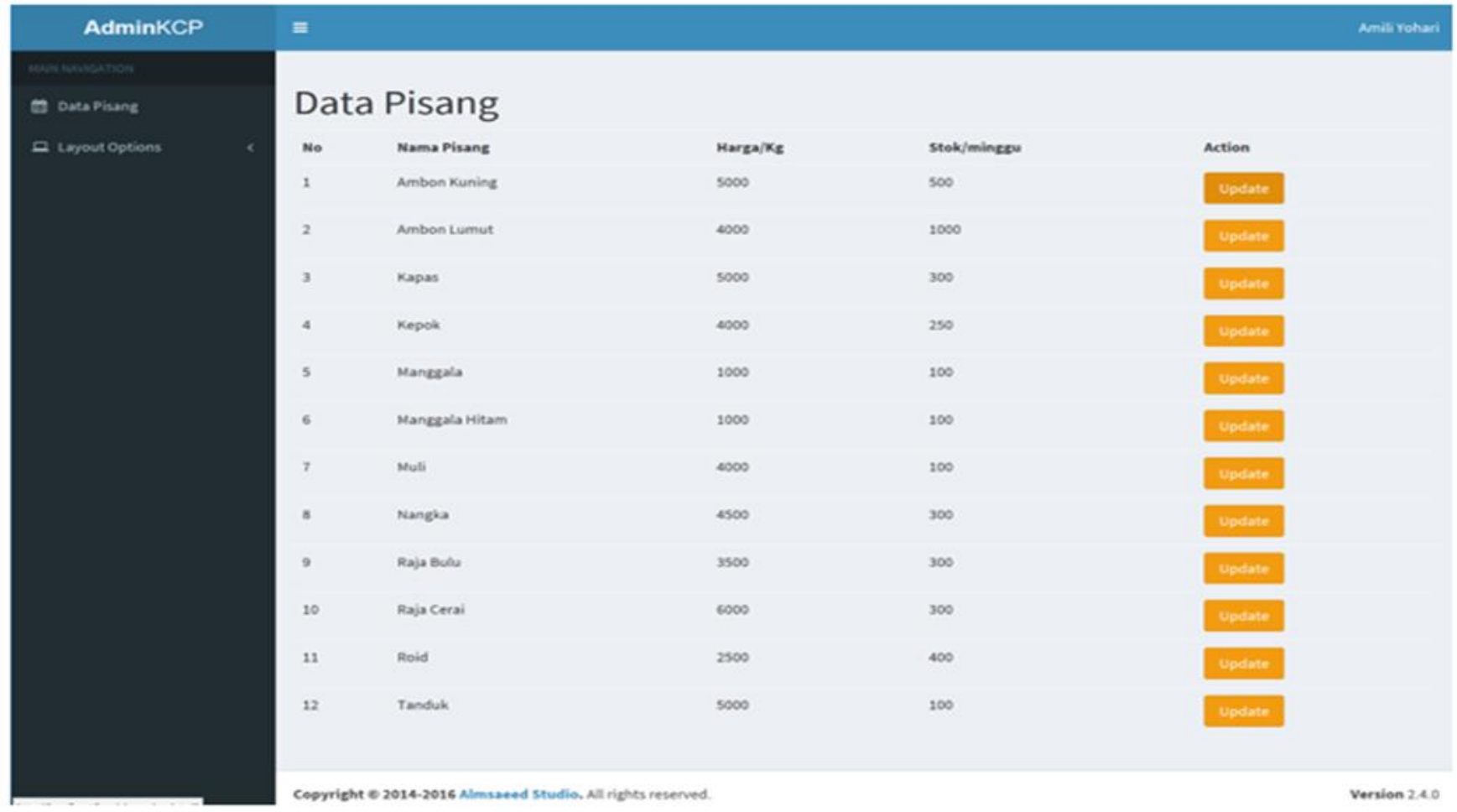

Gambar 6. Tampian Database Pisang KCP

Gambar 6 di atas merupakan tampilan database pisang $\mathrm{KCP}$, mulai dari pisang ambon kuning, ambon lumut, kapas, kepok, manggala, manggala hitam, muli, nangka, raja bulu, raja cerai, roid, dan tanduk. Berikut tampilan untuk memerbaharui tiap data pisang: 


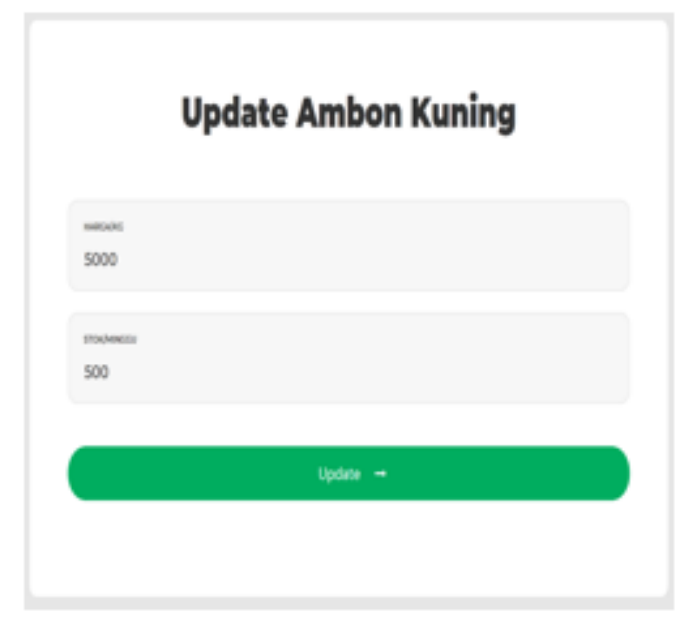

Gambar 7. Tampilan Update Database

Gambar 7 merupakan tampilan jika admin akan memerbaharui data pisang ambon kuning. Setelah tombol Update diklik, data harga dan kapasitas yang ada di halaman utama web, yaitu box pisang ambon, akan otomatis berubah sesuai data yang diinput oleh admin.

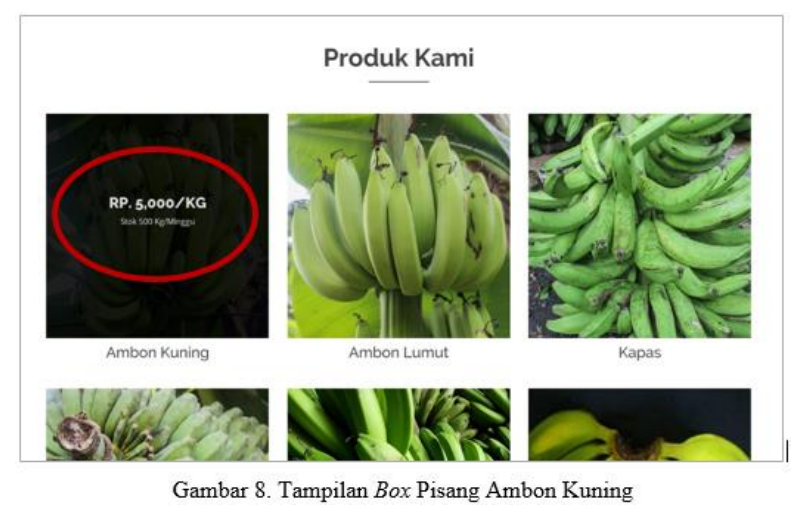

Gambar 8 di atas menampilkan box data harga dan kapasitas pisang yang telah diperbaharui. Pengguna website nantinya selain mengetahui harga dan kapasitas, akan disuguhi dengan penelitian tiap pisang yang ada di KCP. Hal tersebut diinisiasi sebagai langkah pemanfaatan sistem informasi menyebarluaskan ilmu terkait budidaya pisang yang ada di KCP secara gratis. Misalnya informasi terkait produk turunan dari masingmasing pisang lokal yang sangat berguna untuk kemajuan industri yang menggunakan bahan baku pisang sebagai bahan dasar produknya, khususnya industri pangan.

\section{KESIMPULAN}

Petani di Indonesia masih menghadapi berbagai masalah untuk meningkatkan produktivitasnya, baik tentang pengetahuan petani, sumber daya, maupun aktor-aktor yang ada di sektor pertanian. Penelitian atau program yang dibuat sebagian besar tidak berperan banyak karena salah satu alasannya adalah adanya kesenjangan antara ahli atau pemerintah dengan para petani yang sebenarnya ada di lapangan. Namun, bisnis pertanian telah dimasuki oleh sektor digital yang mana setiap informasi mengenai komoditi pertanian dapat ditemukan dan dikumpulkan begitu cepat oleh adanya aplikasi atau sistem informasi seperti website KCP. Website KCP dirancang untuk menghapus kesenjangan dan memecahkan masalah yang ada di sektor pertanian seperti ketidaksesuaian data yang ada antara petani dan lembaga, serta memotong jalur informasi tanpa harus dikumpulkan secara manual dengan mendatangi tiap desa mitra KCP yang ada di beberapa kabupaten se-Jawa Barat. 
Yohari,dkk., SISTEM INFORMASI BERBASIS ...

Perancangan dari website sendiri baru sampai

tahap implementasi yang nantinya akan diuji

dengan menggunakan black-box testing untuk

mengetahui keberhasilan fungsi-fungsi kode

program yang dibuat atau dirancang.

\section{DAFTAR PUSTAKA}

Apăvăloaie, E.-I. 2014. The Impact of the Internet on the Business Environment. Procedia Economics and Finance, 15(14), 951-958. https://doi.org/10.1016/S2212-5671(14)006546.

BPS. 2016. Pisang, Buah Paling Banyak Diproduksi di Indonesia. BPS. Retrieved from https://databoks.katadata.co.id/

FAO. 2016. Produksi Pisang di Indonesia. FAO.

Ismail, A., Hesya, A., Cau, K., \& Kcp, P. (2016). Profil bisnis, 2016, 1-33.

Pujianto, T., Prayudha, A., \& Ardiansah, I. 2017. Application Development To Manage Data And Information On Lettuce Production Companies, 1(1), 9-16.

Situmorang, J. R. 2013. Pemanfaatan Internet Sebagai New Media Dalam Bidang Politik, Bisnis , Pendidikan Dan Sosial Budaya. Jurnal Administrasi Bisnis, 8(2), 77-91. 